Research Article

\title{
Assessment of Cinnamomum tamala (Tejpat) Plantation in Community Forests: A Case Study from Tanahun District
}

\author{
S. Khanal $\left(D,{ }^{1}\right.$ B. K. Tiwari, ${ }^{2}$ and L. Gautam ${ }^{1}$ \\ ${ }^{1}$ Kathmandu Forestry College (KAFCOL), Tribhuvan University, P.O. Box 1276, Amarawati Marga Koteswor, \\ Kathmandu, Nepal \\ ${ }^{2}$ Institute of Forestry (IOF), Pokhara Campus, Tribhuvan University, Pokhara-15, Hariyokharka, Nepal \\ Correspondence should be addressed to S. Khanal; sandhyakhanal082@gmail.com
}

Received 21 January 2021; Revised 20 March 2021; Accepted 2 April 2021; Published 22 April 2021

Academic Editor: Ahmad A. Omar

Copyright (C) 2021 S. Khanal et al. This is an open access article distributed under the Creative Commons Attribution License, which permits unrestricted use, distribution, and reproduction in any medium, provided the original work is properly cited.

\begin{abstract}
Cinnamomum tamala is the major NTFPS cultivated commercially in major parts of Nepal. A research was conducted on the plantation of C. tamala in three research sites, Malayang community forest (CF), Saldada CF, and Banaskhadi CF, of Tanahun district for calculating the survival rate, mortality rate, and overall plant growth performance. Simple stratified random sampling methods were used; height and mean breast diameter $(\mathrm{DBH})$ were measured, and a prestructured questionnaire was used for collecting the data and information from the research sites; also, secondary data from AFO, Tanahun, were used for the analysis of data. The first-year survival rate was the highest (62\%) at Saldada CF and lowest at Banaskhadi CF (35\%); however, the secondyear survival rate was the highest at Saldada CF at 50\%. Mean height: DBH $(\mathrm{cm})$ of the plant was the highest at Saldada CF $(126 \mathrm{~cm})$ and lowest at Banaskhadi $(25 \mathrm{~cm})$. The Pearson correlation analysis at $\alpha=0.05$ was conducted to test the association between mean height and DBH $(\mathrm{cm})$ of $C$. tamala which was $r=0.93, \mathrm{df}=12, p<0.001, r=0.30, \mathrm{df}=11, p<0.001$, and $r=0.88$, $\mathrm{df}=11, p<0.001$, respectively, of Saldada CF, Banaskhadi CF, and Malayang CF. The mean height and mean breast diameter $(\mathrm{DBH})(\mathrm{cm})$ of $C$. tamala were highly correlated in Saldada CF with the highest second-year survival rate. As C. tamala grows well in acidic soil, $\mathrm{pH}$ of all the three research sites was basic, more than 7.5; however, Saldada CF had the highest growth rate than others because the organic matter content was the highest (3.4).
\end{abstract}

\section{Introduction}

Cinnamomum tamala, known as tejpat native to Southeast Asia, is an evergreen tree which belongs to the Lauraceae family that can grow about $1-20 \mathrm{~m}$ tall and be $20 \mathrm{~cm}$ in diameter [1]. It can grow up to $20 \mathrm{~m}$ tall in the forests and farmlands in the Middle Hill Range of Nepal between 450 and 2100 meters above sea level (masl) and is commercially cultivated in Udaypur and Palpa districts and is cultivated well in southwest-facing landscape $[2,3]$. Cinnamomum plant can produce $10-20 \mathrm{~kg}$ dry leaves, and $0.2-0.4 \%$ oil can be extracted from leaves $[4,5]$. C. tamala is a much used species of medicinal and aromatic plants (MAP), found in the wild as well as being cultivated by mountain farmers which helps to meets the requirements of mountain-specific products to enter national, regional, and global value chains
$[5,6]$. Also, children having cough or dysentery can be cured with its seeds ingested with honey or sugar $[5,7]$. Since the early age, C. tamala is used as spice (in local and regional culinary), food, flavour, and pharmaceutical and for the production of essential oils (potential for local value addition also) $[4,6]$.

Height: diameter ratio, being an individual tree-based index, is calculated by dividing the height of the crop tree by the diameter [8]. The relationship between tree diameter at breast height and tree height is the most commonly used measurement of the tree size [9]. Site factor, climatic factor, and other conditions affect the height-diameter profile, survival, and mortality rate of every plant species and also plants of the same species, so the site and its condition must be known before plantation $[10,11]$. Soil $\mathrm{pH}$ can affect the availability of nutrients and activity of many essential 
microorganisms [12]; the soil roughly contains $50-60 \%$ of mineral matter, $20-35 \%$ of water, $15-25 \%$ of air, and little percentage of organic matter.

Every year, a huge amount of budget is spent for seedling development and plantation; however, all the efforts for the establishment of plantation become unsuccessful due to the lack of assessment of survival and huge mortality within the plantation site of seedlings [13]. Although few studies have been performed for the survival rate and growth performance of C. tamala in Nepal, scientific study of their survival rate, mortality, and growth performance on various soil types was not performed before. To overcome these limitations, a study was carried out for the status of $C$. tamala by assessing the survival rate, mortality rate, and growth performance on Tanahun districts in Saldada community forest (CF), Malayang CF, and Banaskhadi CF of Myagde Rular Municipality.

\section{Method and Methodology}

2.1. Study Site. The study was carried out at Saldada CF, Banaskhadi CF, and Malayang CF which were established in 2018 and 2019 ( $2^{\text {nd }}$ and $1^{\text {st }}$ year of plantation), respectively, and at Myagde Rular Municipality, Tanahun district (Table 1). The latitude and longitude of the research area were $27^{\circ} 54^{\prime} 59.99^{\prime \prime} \mathrm{N}$ and $84^{\circ} 14^{\prime} 60.00^{\prime \prime} \mathrm{E}$, respectively (Figure 1).

2.2. Survival Rate and Cause of Mortality. Survival percentage was calculated by simple formulae, calculating the total plant survived in the $2.5 \mathrm{~m}^{2}$ area and calculating the total number of plants planted in the same area.

Survival percentage $=($ total plants survived in the research area/total plants planted) $* 100 \%$.

A semistructured questionnaire was used for the user's groups and farmers for 106 households involved in the plantation to obtain information from respondents about the cause in the research site.

2.3. Measuring the Growth Stage. For assessing the growth stage of the C. tamala plant, the following parameters were compared with the values/data taken during the plantation year:

(i) Height of the plant $(\mathrm{cm})$ : height of the plant was taken from the ground surface to the top of the plant with the help of a tape and bamboo stick

(ii) Collar diameter of the plant $(\mathrm{cm})$ : collar diameter of the plant was taken at $10 \mathrm{~cm}$ from the soil surface with the help of a tape or rope

(iii) Height: collar diameter ratio: the mean value of height and diameter of each site was calculated

2.4. Soil Data. The soil sample at depth $0-15 \mathrm{~cm}$ was collected from the centre of each plot by means of a metal soil corer of $4 \mathrm{~cm}$ diameter and placed in a labelled sample bag. The collected sample was brought to the laboratory to determine the organic matter and soil $\mathrm{pH}$. The soil organic matter in the laboratory was determined by the colorimetric determination of soil organic matter process.
2.5. Methods of Data Analysis. All the collected data were entered in MS Excel version 19, and data analysis was performed with the help of MS Excel and RStudio. Correlation analysis was computed by using RStudio. Graphs and bar diagram were generated from MS Excel. Analysis of variance (ANOVA) was computed with the help of RStudio.

\section{Results and Discussion}

3.1. Survival Rate. Saldada CF research site is located on the slope at the southern-western aspect having higher survival rate of $62 \%$ among all the three sites, compared to Banaskhadi CF which was at the southern-eastern aspect and with abundance of slate mine on the past, having lowest survival rate with $35 \%$ in their first year of plantation (Figure 2(a)), whereas Malayang CF and Saldada CF were at their second year of plantation stage; second-year survival rate was found to be $50.80 \%$ higher than that of Malayang CF which has both southern-eastern and northern aspects of the plantation (Figure 2(b)).

It was found that the Saldada CF research site was favoured by its aspects. The first-year survival rate of Cinnamomum at Saldada CF was found to be $62 \%$ which is similar to the finding of Paudel and Acharya [13], where the first-year survival rate of Cinnamomum was 60\%; however, it has vast difference with Banaskhadi CF. Cryptocarya is found to be favoured by shade trees in the early stage of growing most of Cryptocarya plant have died during the dry period; the poor performance was due to photoinhibition which was reported by Erskine et al. [11]; similar things were taken into consideration for Banaskhadi CF where no shade trees were planted on the field. Also, Tanahun district NTFPs' book published by DFO, Tanahun, reported that growth of Cinnamomum is favoured by shade up to the age of 4-5 years [2]; this indicates that the aspect and shade tree need to be considered during the site selection for the plantation of C. tamala in the area.

3.2. Mean Height vs. DBH. Though the three research sites were at different locations and altitude, they have almost similar habitat and weather conditions. Among two sites, Saldada CF and Malayang CF, which were at their second year of plantation, the highest growth performance of the plant was found at the Saldada CF site, recording the tallest height of the seedling to be $126.6 \mathrm{~cm}$ and smallest height of the seedling to be $51 \mathrm{~cm}$, whereas tallest height of the 2ndyear plant of Banaskhadi CF was $88.75 \mathrm{~cm}$ tallest among and smallest to be $56 \mathrm{~cm}$, (Figure 3). Very small increase in height with the increase in diameter was observed from all three research sites. Banaskhadi CF site has seedling of $1^{\text {st }}$ year plantation, the tallest seedling was recorded to be 26.33 $\mathrm{cm}$ height and smallest height to be $23 \mathrm{~cm}$. (Figures 3 and 4).

The mean height: diameter ratio of the Banaskhadi CF is was lowest because of the first year of plantation as plants had no growth and developed properly, whereas the height: diameter ratio of the Saldada CF and Malayang CF has highest because the seedling are on the second year of the plantation (Figures 2(a), 2(b), and 4) [3, 9]. 
TABLE 1: Study area and details of the three community forests.

\begin{tabular}{lccc}
\hline Name of CFUG & Saldada CF & Malayang CF & Banaskhadi CF \\
\hline Geographic region & Midhill & Midhill & Midhill \\
Rular Municipality & Myagde-5 & Myagde-5 & Myagde-5 \\
Management practice & Community & Community & Community \\
Area of plantation (hectare) & 3.2 & 5.6 & 3.8 \\
Forest type & Natural & Natural & Natural \\
Year of plantation & 2018, June & 2018, June & 2019, June \\
\hline
\end{tabular}

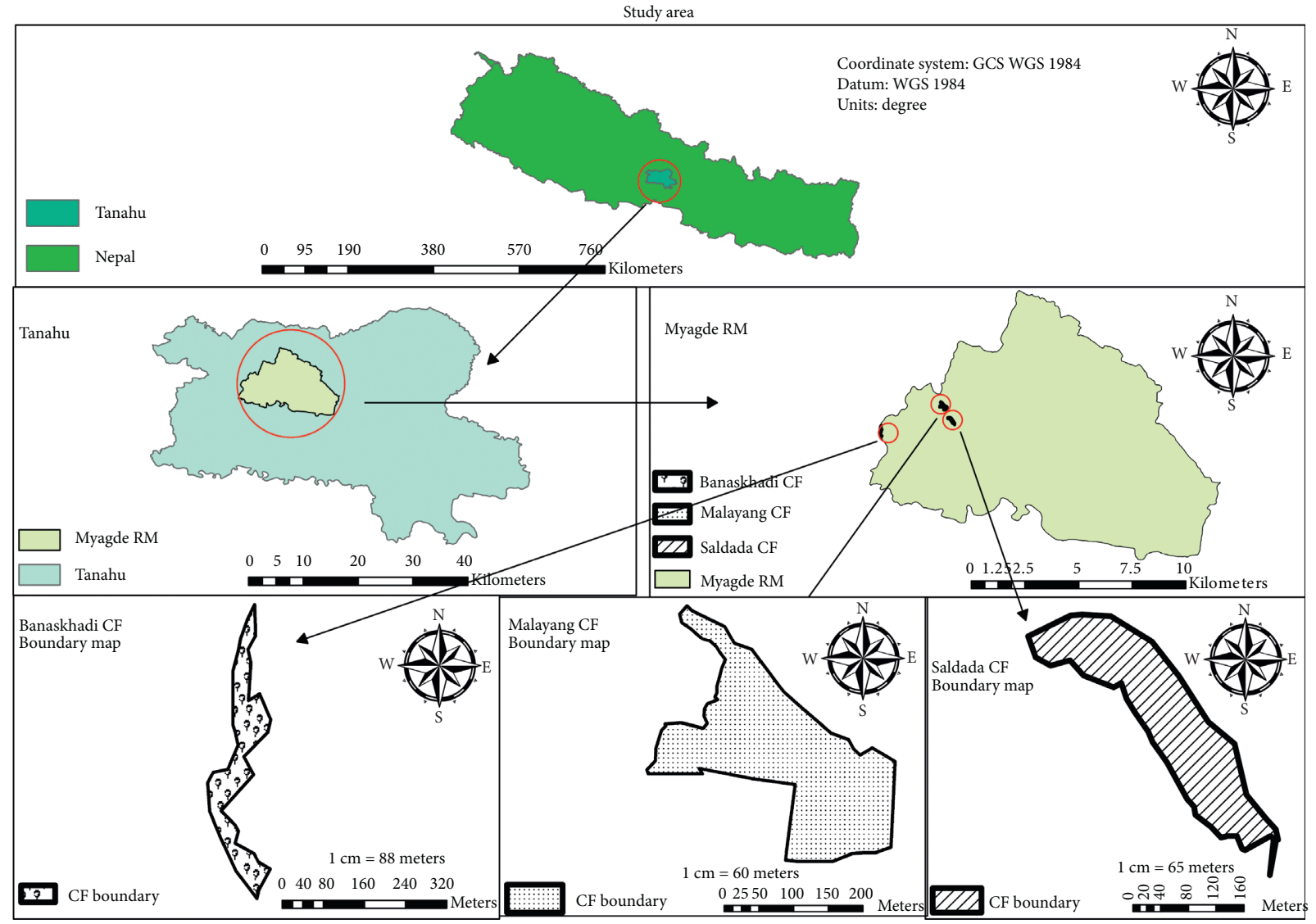

FIGURE 1: The three different study areas of the research.

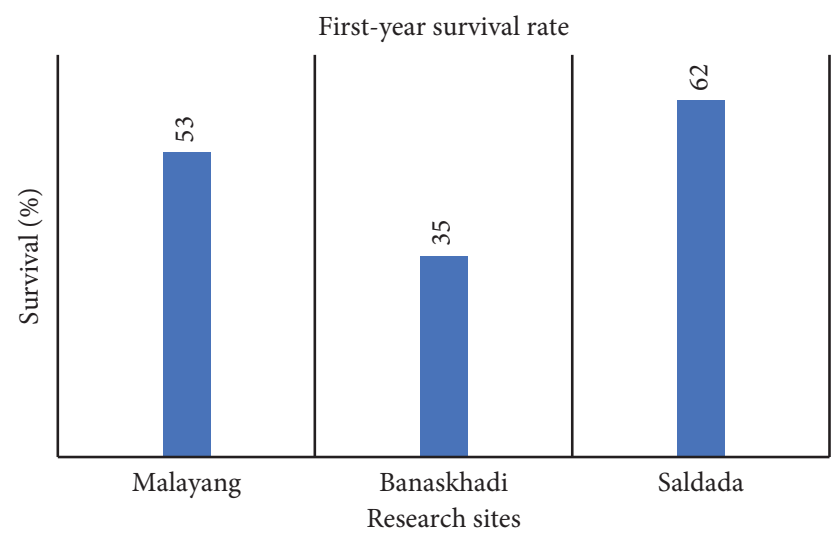

(a)

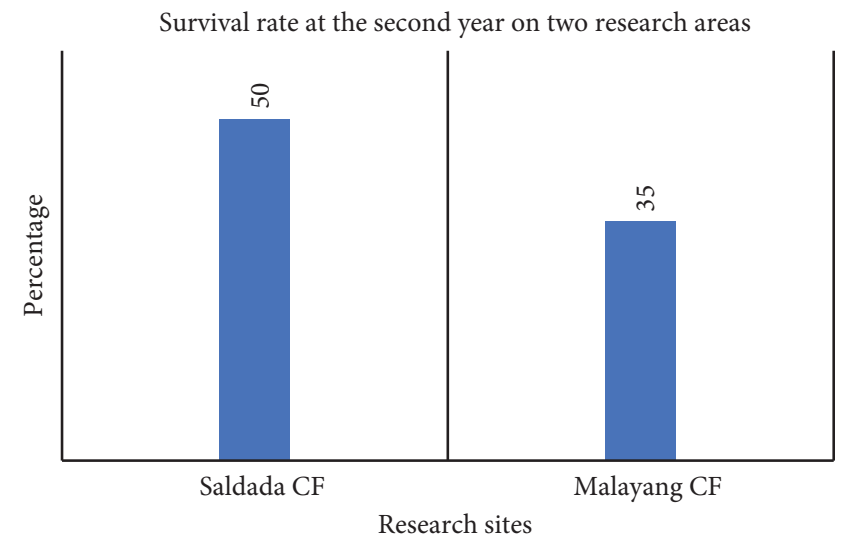

(b)

Figure 2: (a) First-year survival rate and (b) second-year survival rate of $C$ tamala on three community forests. 


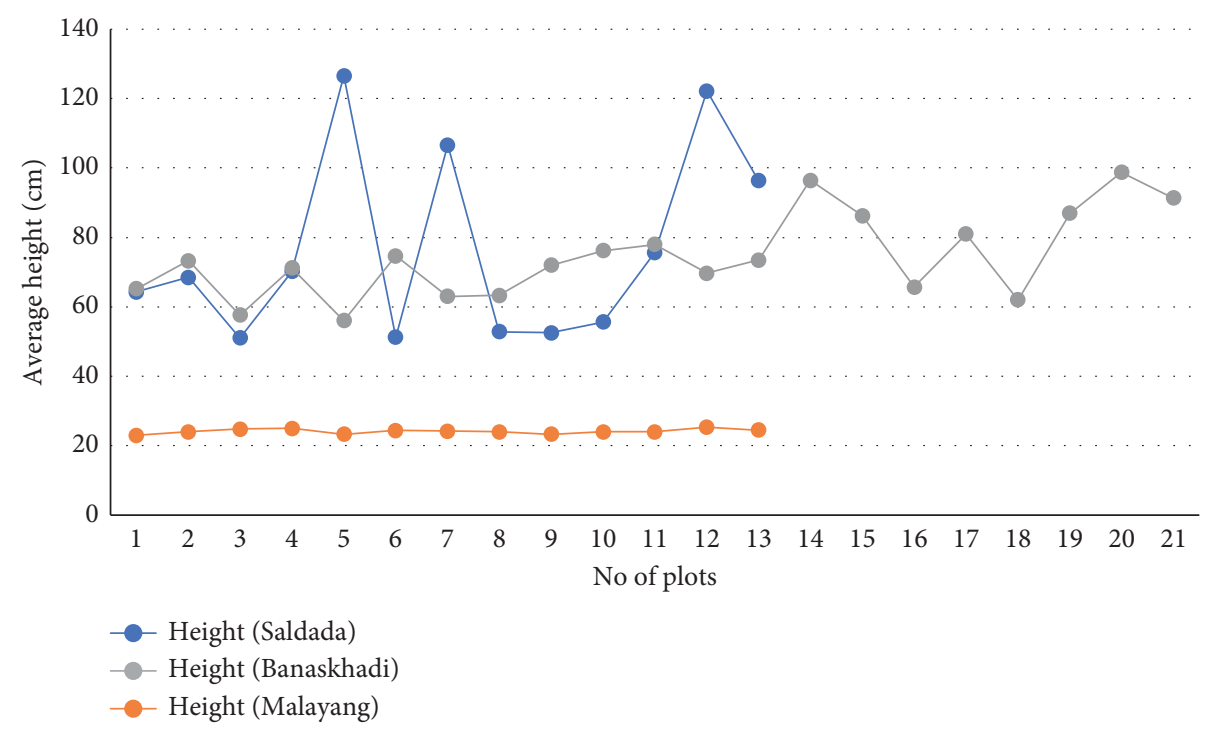

FIGURE 3: The average height of plants on three different research sites.

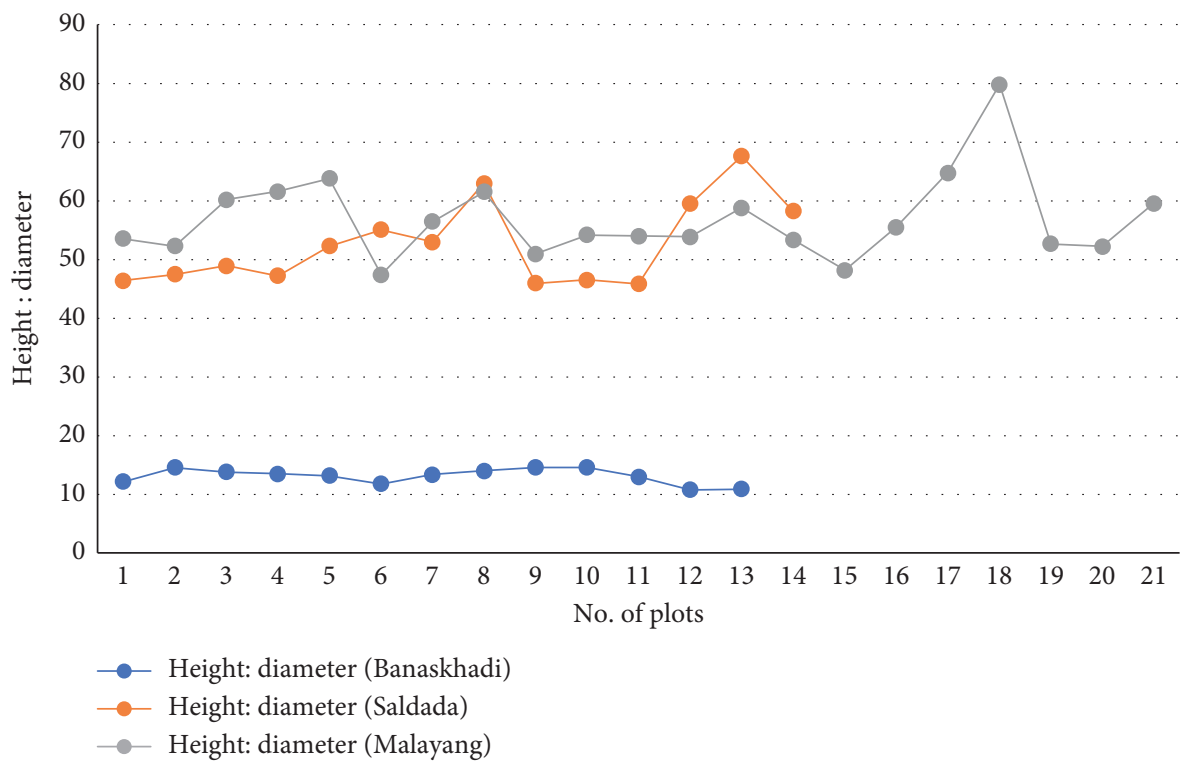

FIgURE 4: The height: diamater ratio of the plants on three research sites.

A linear increase in both diameter and height of the tree was found in most of vigorously growing trees, and trees with declining diameter growth rate exhibited asymptotic toward height growth [9].

\subsection{Result and Discussion of Soil pH and Organic Matter}

3.3.1. Soil pH. $\mathrm{pH}$ of 2 sites, Malayang CF and Banaskhadi $\mathrm{CF}$, was found to be neutral with range 7.4 and 7.5, whereas $\mathrm{pH}$ of Saldada CF was found to be alkaline with $\mathrm{pH}$ 7.6. The organic matter content of Saldada CF and Malayang CF was found to be medium among which Saldada CF had the maximum amount of $\mathrm{OM}$ (3.31), and Malayang CF had 3.17, whereas the organic matter content of Banaskhadi CF was found to be low with 2.4. Saldada CF had the maximum amount of OM among all the three sites (Table 2).

Soil $\mathrm{pH}$ plays a vital role in plant growth and its production. Imbalance soil $\mathrm{pH}$ or $\mathrm{pH}$ range of soil that does not fit the plant can lead to the failure of plantation. According to the DPR [2], soil pH at the range of 4 to 5.5 (acidic pH) is best for the growth of Cinnamomum [10,12]. From the lab test report, none of the sites have acidic soil $\mathrm{pH}$ which can be the major cause of the failure of plantation. Alkaline soil $\mathrm{pH}$ could be one of the reasons for low survival rate. OM content of all the three sites was found to be low as needed by 
TABLE 2: $\mathrm{pH}$ and percentage of the organic matter content of the soil in three research sites.

\begin{tabular}{lccc}
\hline S. no. Community forest name & $\mathrm{pH}$ & $\mathrm{OM} \mathrm{( \% )}$ \\
\hline 1 & Saldada CF & 7.6 (alkaline) & 3.42 (medium) \\
2 & Saldada CF & 7.6 (alkaline) & 3.20 (medium) \\
3 & Banaskhadi CF & 7.5 (neutral) & 2.59 (medium) \\
4 & Banaskhadi CF & 7.5 (neutral) & 2.32 (low) \\
5 & Malayang CF & 7.4 (neutral) & 3.32 (medium) \\
6 & Malayang CF & 7.3 (neutral) & 3.038 (medium) \\
\hline
\end{tabular}

pH; > IF > 7.5, "Alkaline," IF > 6.4, "Neutral," "Acidic."

OM: =IF $>5$, "High," IF > 2.4, "Medium," "Low."

$\mathrm{N}: \mathrm{IF}>0.2$, "High," IF $>0.1$, "Medium," "Low."

P2O5 : IF > 55, "High,"> 31, "Medium," "Low."

$\mathrm{K} 2 \mathrm{O}:$ IF $>280$, "High," IF $>110$, "Medium," "Low").

Note: soil OM was determined by the colorimetric determination of soil organic matter process.

C. tamala for its growth. C. tamala thrives well in soil with the high amount of $\mathrm{OM}[2,12,14]$. Less amount of OM could also be the reason for low survival rate in Banaskhadi CF and Malayang CF in comparison with Saldada CF which had a bit more OM content than the other two CFs.

3.4. Statistical Analysis. A parametric correlation (Pearson) $(\alpha=0.05)$ was performed to test the association between mean height and mean breast diameter (DBH) (cm) of C. tamala. A significant correlation was found between the mean height and mean breast diameter $(\mathrm{DBH})(\mathrm{cm})$ of C. tamala of Banskhadi CF at $r=0.54$, $\mathrm{df}=11$, and $p<0.001$.

There was a significant linear relationship between mean height and mean breast diameter $(\mathrm{DBH})(\mathrm{cm})$ of C. tamala of Banaskhadi CF $\left(R^{2}=0.30, F_{(1,11)}=68.4\right.$, $p>0.001)$. A parametric correlation (Pearson) $(\alpha=0.05)$ was performed to test the association between mean height and mean breast diameter $(\mathrm{DBH})(\mathrm{cm})$ of C. tamala. A significant correlation was found between the mean height and mean breast diameter $(\mathrm{DBH})(\mathrm{cm})$ of C. tamala of Saldada CF at $r=0.93, \mathrm{df}=12$, and $p<0.001$. There was a significant linear relationship between mean height and mean breast diameter $(\mathrm{DBH})(\mathrm{cm})$ of C. tamala of Malayang CF $\left(R^{2}=0.88, F_{(1,12)}=88.1\right.$, $p>0.001)$.

There was a positive correlation between mean height and mean steam diameter $(\mathrm{DBH})$ of $C$. tamala on two community forests, Banaskhadi CF and Saldada CF, 0.54 and 0.93 , respectively. And the higher second-year survival rate of the plants shows the positive relation site specific, so we can draw the conclusion that seedlings were well adapted to the environment and performed well. Cryptocarya erythroxylon and C. tamala are plants that fall under the same family. Height of Cryptocarya erythroxylon was found to increase in between 10 and $30 \mathrm{~cm}$ in the first year and around $80-100 \mathrm{~cm}$ in the second year. The result of this study shows the similar growth performance of height in C. tamala. Cryptocarya was found to rarely grow faster than $6 \mathrm{~cm}$ per month and found to be benefited by shade trees $[11,15]$. A positive correlation between stem diameter and height was found $[8,11,15]$.

\section{Conclusion}

The survival rate of C. tamala at Saldada CF at the first year was found to be $62 \%, 53 \%$ at Malayang CF, and $35 \%$ at Banaskhadi CF. The survival rate of Saldada CF was found to be highest among the three sites as Saldada CF was favoured by its aspects in comparison to Banaskhadi CF and Malayang CF. Total area of Saldada CF was at southwest landscape, while almost all areas of Banaskhadi CF were at the southern-eastern aspect, and mixed aspect was found at Malayang CF. Survival rate, growth performance at Saldada $\mathrm{CF}$ was found to be favoured by its aspect among all three sites, because of proper weeding survival rate and growth performance were also better than other site and also due to nearer user group.

Mortality of Banaskhadi CF was found to be more due to the small size of the plant, unfavourable site Cinnamomum tamala is favoured at southern-western aspect, but the plantation site of Banaskhadi CF is at the southern-eastern aspect because of which direct sunlight is faced by the seedling the whole day which increases the mortality rate. Banaskhadi CF plantation site was on the slate mine as the slate was extremely rocky with small and large stones, and also, the site was totally cleaned before plantation without any shade trees which causes an increase in mortality of the plant.

Soil $\mathrm{pH}$ required for Cinnamomum was acidic, but from the test, alkaline and neutral $\mathrm{pH}$ was observed. Soil OM required for the plant was high, but none of the sites had high OM content; also, Banaskhadi CF had low OM content as per the lab report. We can conclude that soil of all the three sites does not support C. tamala and its growth, and the lack of soil quality as required can be concluded as the prime cause of the failure of plantation in Banaskhadi CF, whereas a combination of multiple causes such as lack of weeding as improper soil quality can be the cause for Malayang CF.

\section{Data Availability}

The data used to write this report are primary data collected through a survey and prestructured questionnaire. All the raw and processed data are available from the corresponding author upon request.

\section{Conflicts of Interest}

The authors declare that they have no conflicts of interest.

\section{Acknowledgments}

The authors would like to express their deepest gratitude to their advisor Mr. Laxman Gautam for his continued support and encouragement throughout the whole study period. The authors are also grateful to the staff of DFO, Tanahun, for providing necessary information on community forests of Tanahun district. This work was supported by Vyash $\mathrm{Mu}-$ nicipality, Tanahun, for the higher study research grant for fiscal year 2019-2020. 


\section{References}

[1] B. H. Pandit, G. B. Thapa, and M. Zoebisch, "Promoting marketing of cinnamon tree products in Palpa district of Nepal," 2010.

[2] DPR (Government of Nepal), "Asal Kheti Tatha Sankalan Aavyash,” 2017, https://dpr.gov.np/en/category/publication/ report/.

[3] D. P. Parajuli, "Cultivation of Cinnamonum tamala on marginal lands for greater income at Palpa district," Banko Janakari, vol. 8, no. 1, pp. 24-32, 1997.

[4] D. Lamichhane and N. Karna, "Harvesting methods of Cinnamomum tamala leaves in private land: a case study from Udayapur district, Nepal," Banko Janakari, vol. 19, no. 2, pp. 20-24, 2010.

[5] S. Nabavi, A. Di Lorenzo, M. Izadi, E. Sobarzo-Sánchez, M. Daglia, and S. Nabavi, "Antibacterial effects of Cinnamon: from farm to food, cosmetic and pharmaceutical Industries," Nutrients, vol. 7, no. 9, pp. 7729-7748, 2015.

[6] S. P. Upadhaya, M. Kirihata, and I. Ichimoto, "Cinnamon leaf oil from Cinnamomum tamala grown in Nepal," Nippon Shokuhin Kogyo Gakkaishi, vol. 41, no. 7, pp. 512-514, 1994.

[7] M. Sundriyal, R. C. Sundriyal, and E. Sharma, "Dietary use of wild plant resources in the Sikkim Himalaya, India," Economic Botany, vol. 58, no. 4, pp. 626-638, 2004.

[8] T. Buba, "Relationships between stem diameter at breast height $(\mathrm{DBH})$, tree height, crown length, and crown ratio of Vitellaria paradoxa CF Gaertn in the Nigerian Guinea Savanna," African Journal of Biotechnology, vol. 12, no. 22, pp. 3441-3446, 2013.

[9] A. Sumida, T. Miyaura, and H. Torii, "Relationships of tree height and diameter at breast height revisited: analyses of stem growth using 20 year data of an even-aged Chamaecyparis obtusa stand," Tree Physiology, vol. 33, no. 1, pp. 106-118, 2013.

[10] Y. Chen, "Quality change of cinnamon soil cultivated land and its effect on soil productivity," Scientia Agricultura Sinica, vol. 52, no. 24, pp. 4540-4554, 2019.

[11] P. D. Erskine, D. Lamb, and G. Borschmann, "Growth performance and management of a mixed rainforest tree plantation," New Forests, vol. 29, no. 2, pp. 117-134, 2005.

[12] N. Bhuyan and S. Sharma, "Physico-chemical analysis of soil status of various degraded sites in an around Dimoria tribal belt of Assam, India," International Journal of Science and Research (IJSR), vol. 8, no. 6, pp. 849-852, 2017.

[13] G. Paudel and R. Acharya, "Survival status of young plantations in Parbat district, Nepal," Banko Janakari, vol. 27, no. 3, pp. 21-26, 2018.

[14] W. Lin, J. Cai, and L. Xue, "Short-term interactive effects of nitrogen and phosphorus additions and different planting densities on soil chemical properties of Cinnamomum camphora seedlings," Acta Ecologica Sinica, vol. 39, no. 24, pp. 9162-9170, 2019.

[15] S. R. Menggala, W. Vanhove, D. R. A. Muhammad, J. Hendri, S. Speelman, and P. Van Damme, "Sustainable harvesting of Cinnamomum burmannii (Nees \& T. Nees) blume in kerinci regency, Indonesia," Sustainability, vol. 11, no. 23, p. 6709, 2019. 